\title{
Interrelationship Analysis of L-Band Backscattering Intensity and Soil Dielectric Constant for Soil Moisture Retrieval Using
} PALSAR Data

\author{
Saeid Gharechelou, Ryutaro Tateishi, Josaphat Tetuko Sri Sumantyo \\ Center for Environmental Remote Sensing (CEReS), Chiba University, Chiba, Japan \\ Email: acfa3286@chiba-u.jp
}

Received 24 December 2014; accepted 9 February 2015; published 13 February 2015

Copyright (C) 2015 by authors and Scientific Research Publishing Inc.

This work is licensed under the Creative Commons Attribution International License (CC BY). http://creativecommons.org/licenses/by/4.0/

(c) $\underset{\mathrm{EY}}{\mathrm{Br}}$ Open Access

\begin{abstract}
The purpose of this paper is to study about the interrelationship between the backscattering intensity of PALSAR data and the laboratory measurement of dielectric constant and soil moisture. The characterization of the dielectric constant of arid soils in the 0.3 - $3 \mathrm{GHz}$ frequency range, particularly focused in L-band was analyzed in varied soil moisture content and soil textures. The interrelationship between the relative dielectric constant with soil textures and backscattering of PALSAR data was also analyzed and statistical model was computed. In this study, after collecting the soil samples in the field from top soil $(0-10 \mathrm{~cm})$ in a homogeneous area then, the dielectric constant was measured using a dielectric probe tool kit. For investigated of the characteristics and behaviors of the dielectric constant and relationship with backscattering a variety of moisture content from $0 \%$ to $40 \%$ and soil fraction conditions was tested in laboratory condition. All data were analyzed by integrating it with other geo-physical data in GIS, such as land cover and soil texture. Thus, the regression model computed between measured soil moisture and backscattering coefficient of PALSR data which were extracted as same point of each soil sample pixel. Finally, after completing the preprocessing, such as removing the speckle noise by averaging, the model was applied to the PALSAR data for retrieving the soil moisture map in arid region of Iran. The analysis of dielectric constant properties result has shown the soil texture after the moisture content has the largest effected on dielectric constant. In addition, the PALSAR data in dual polarization are also able to derive the soil moisture using statistical method. The dielectric constant and backscattering shown have the exponential relationship and the HV polarization mode is more sensitive than the HH mode to soil moisture and overestimated the soil moisture as well. The validation of result has shown the 4.2 Vol-\% RMSE of soil moisture. It means that the backscattering analysis should consider about other factors such a surface roughness and mix pixel of vegetation effective.
\end{abstract}


Keywords

SAR, Dielectric Constant, Soil Moisture, Arid Soil, Backscattering, Soil Texture, PALSAR Data

\section{Introduction}

In recent years, the Synthetic Aperture Radar (SAR) becomes one of the special applicable methods in land remote sensing. A remote sensing scientist has approached to SAR application due to an optical sensor limitation, particularly when it uses the optical data. The soil moisture has a key role in analyzing land cover change, hydrological model, agriculture application and the application in ecosystem management. SAR observations data of the Earth's physical surface have great potentials to information production, since the backscattered radar signal depends on the volumetric moisture content of soil layer. Many researchers in remote sensing approach trying to find out the algorithms for extracting information's from the Earth's surface (e.g. soil properties) due to its potential where there are difficulties for access to a study area frequently and revisit for measuring and monitoring with low cost.

In the active and passive microwave remote sensing, the dielectric constant is the most important parameter for the study of soil properties particularly soil water content. The SAR backscattered signal from soil is sensitive to surface parameters mainly to soil moisture and surface roughness. In microwave soil moisture remote sensing, determining the soil moisture by measuring the value of dielectric constant is important. This is because of the emissivity and backscattering coefficient of soil at each frequency is simulated and the soil moisture on the ground surface is extracted from the satellite data. In an alternating electric field, permittivity varies with applied frequency [1] [2].

A knowledge of the dielectric constant properties such an emissivity and permittivity of the soil is useful for the efficient use of soil and for sensor design in microwave remote sensing [1] [3]. The dielectric constant depends on the type of material as well as its moisture state [2] [4]-[7]. These dielectric properties are going to be functions of signal frequency, the amount and nature of water content in the soil, the chemical characteristics of the soil such as minerals and organic matters, and the physical properties of the soil such as its structure, texture and its bulk density [1] [8]. The base for microwave remote sensing of soil moisture is strongly dependence on its water content due to the large contrast between the dielectric constant of Air (1), water (80) and dry soil (3 - 5) [1] [9] [10]. The dielectric constant of soil is the physical property being very sensitive on water content.

There are several reports for finding their own studies on dielectric constant in soil particularly in wet soil with developed soil layers and not often research has down in the arid region for dry soil with undeveloped soil layer and less organic matter [11]-[14]. Arid soils occupy around 12\% of the Earth's ice-free land area [15]. But, no deep knowledge is available about the mineral soil in arid area. This research aims to study about the dielectric constant properties of arid soil.

Many types of remote sensing data and active and passive microwave can be used in the methods for soilmoisture estimation [16]-[19]. By understanding the electromagnetic scatterings previously, some theoretical models which can generate the soil moisture such as Integral Equation Model (IEM) and standard Small Perturbation (SP) Model have been developed. Beside the scatter model, the statistical methods are used to retrieve the soil moisture as well. This statistical method is based on calculations on the data to appeal a relationship between variables [2]. In active microwave remote sensing, the scatter from the remote sensing sensor information and the field soil moisture and dielectric constant are variables. A linear regression analysis is represented mostly by a statistical method [20]. Many statistical methods that have been realized to retrieve soil moisture are based on converting the emitted microwave radiation, from the surface to the sensor, into mathematical values that can be statistically analyzed [21].

This study consists of field and laboratory experiments intended to characterize the relative dielectric constant of arid soils, in the $0.3-3 \mathrm{GHz}$ frequency range. The interaction between soil moisture content, soil types and dielectric constant is also covered and findings are applied the statistical method to PALSAR data for retrieving the soil moisture.

\section{Study Area and Field Work}

The study area is located in northern part of Iran (Figure 1). The climate type of study area is arid and semi-arid, 


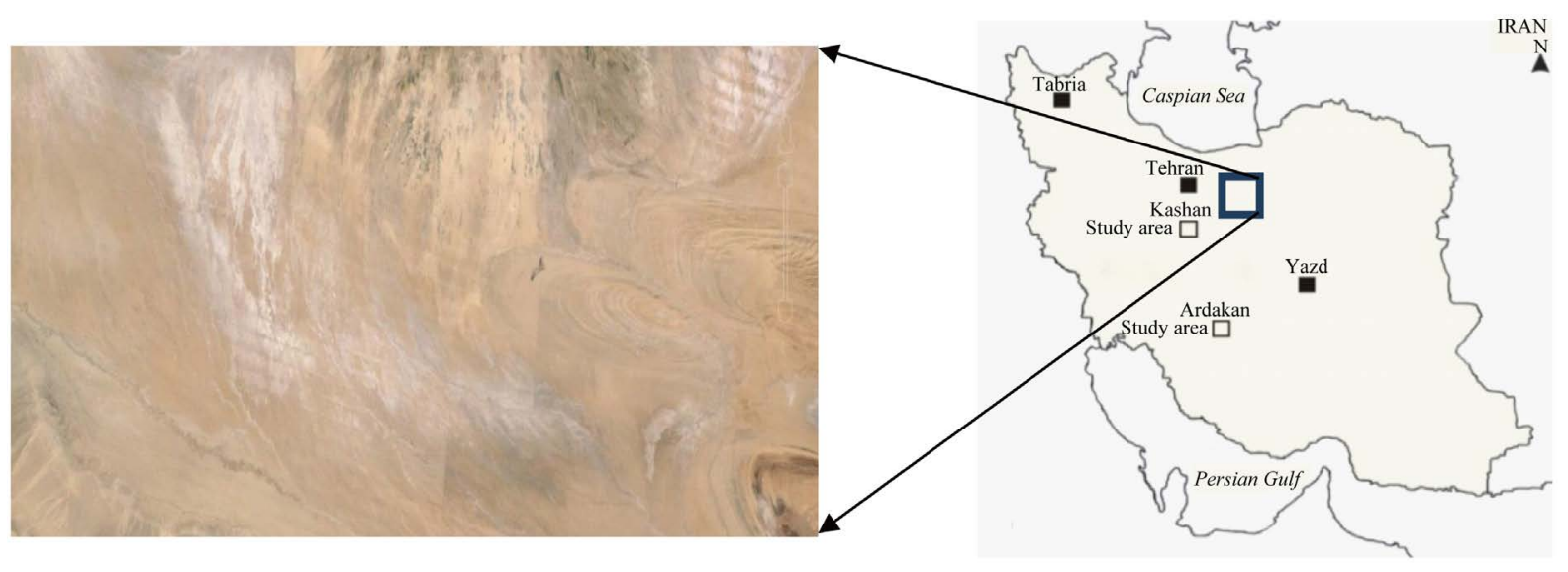

Figure 1. The study area using Google Earth image.

and the average of annually precipitation is $120 \mathrm{~mm}$. According to the temperature and humidity regime of soil classification, the soil of this region is categorized in Aridic. The soil in arid region in the US soil taxonomy categorized on Aridisols class (from Latin aridus, "dry”) exhibits at least some subsurface horizon development [15]. Land use of this area is mainly range, wildlife, recreation and non-used and agriculture and land cover in study area is mostly the bare land, sparse vegetation and cropland in north part. Aridisols have a very less concentration of organic matter, reflecting the paucity of vegetative production on these dry soils.

\section{Data Sets}

\subsection{Satellite Remote Sensing Imagery}

The Advanced Land Observing Satellite (ALOS) Phased Array L-Band Synthetic Aperture Radar (PALSAR) image from September 16, 2010 was acquired for the study area in the Fine Beam Mode (FBD). We have been acquired the SAR data in dry season which is in September as the driest month in study area with the lowest precipitation. The information of the SAR dataset is shown in Table 1. Before using the SAR data, radiometric calibration, filter processing, speckle noise removing and geometric correction were done (Figure 3).

\subsection{Field Observation and Laboratory Experiment Data}

We went to field work on September, 2012 at the same month of PALSAR data for soil sampling from $0-10 \mathrm{~cm}$ top soil. In addition in the field observation, the land cover and surface roughness were investigated. The thirty five samples were collected and transported to the laboratory for experiment analysis. Sampling method was randomly in each land unit base on homogenous area which was made by land unit map. In each sample point on the four directions with $10 \mathrm{~m}$ distance sample token and after mixing the one sample prepared. To overcome the uncertainties of the dielectric constant values for the different types of soil and moisture conditions measured by TDR (Time domain reflectance). Soil samples were collected for dielectric constant and soil moisture content analysis in the laboratory in Table 2. The properties of the some measured soils are presented.

The measurement of the dielectric constant was performed in seven steps by changing the moisture constant of each sample in the natural field soil, 10\%, 20\%, 30\%, $40 \%$ and saturated soil, and finally oven soil (Figure 2). In order to reduce the error on the obtained values, the same measurements were repeated five times. Considering the cap sizes in Figure 2, the according the sample volume in $\mathrm{ml}$ and the water volume for each studied water volume are presented on Table 3.

For each soil texture, the measurement procedure was the following:

- Measurement of the soil moisture of natural filed by TDR, weighed the samples then, measured the dielectric constant.

- To completely dry the soil inside an oven at $110^{\circ} \mathrm{C}$ in $24 \mathrm{hr}$.

- Introduction of the soil sample inside the regular cup and to weight it after sieving the gravel.

- Dielectric tool kit calibration.

- Measurement of sample's dielectric constant. 
Table 1. The acquired SAR images in study are.

\begin{tabular}{cc}
\hline Frequency GHz (band) & 1.27 (L-band) \\
\hline Wavelength $(\mathrm{cm})$ & 23.62 \\
Polarization & $\mathrm{HH}, \mathrm{HV}$ \\
Acquisition mode & FBD \\
Processing level & 1.1 \\
Orbit ascending & Ascending \\
Acquisition date & 16.9 .2010 \\
\hline
\end{tabular}

Table 2. Physical properties of soil samples in study area.

\begin{tabular}{|c|c|c|c|c|c|c|c|c|}
\hline Field No. & Soil texture & Sand\% & Silt\% & Clay\% & $\begin{array}{l}\text { Bulk density } \\
\qquad\left(\mathrm{g} / \mathrm{cm}^{3}\right)\end{array}$ & $\begin{array}{c}\text { TDR soil } \\
\text { moisture } \%\end{array}$ & $\begin{array}{c}\text { Gravimetric soil } \\
\text { moisture } \%\end{array}$ & Land cover \\
\hline 23 & Loam & 30.2 & 54.1 & 15.7 & 1.58 & 3.3 & 4.12 & Sparse vegetation \\
\hline 21 & Silt loam & 18.2 & 68.2 & 13.6 & 1.82 & 8.6 & 7.92 & Bare land \\
\hline 14 & clay & 51.6 & 33.3 & 15.1 & 1.60 & 10.6 & 9.6 & Bare land \\
\hline 9 & Silt clay & 9 & 52 & 39.1 & 1.50 & 25 & 27.11 & Sparse vegetation \\
\hline 1 & Sand & 82.1 & 12.6 & 5.3 & 2.30 & 2.3 & 1.8 & Bare land \\
\hline
\end{tabular}

Table 3. Water quantity vs. volumetric soil moisture.

\begin{tabular}{cc}
\hline Soil moisture volumetric (\%) & Water volume (ml) \\
\hline 10 & 15 \\
20 & 24 \\
30 & 41 \\
40 & 57 \\
\hline
\end{tabular}

- Introduction of $15 \mathrm{ml}$ of water (10\% water content) uniformly distributed in the cavity.

- Weight of the new sample for gravimetric soil moisture.

- Measurement of samples dielectric constant for each soil type and computation of the dielectric constant for the next water content for instance $20 \%$ then repeat for same soil type.

\section{Analysis Method}

\subsection{Image Preprocessing for PALSAR}

In this study, the PALSAR image was converted from the provided format in the Digital Number (DN) values, to the backscattering intensity information also known as the backscattering coefficients or the normalized Radar cross section expressed using Equation (1):

$$
\sigma^{\circ}=10 \times \log 10(\mathrm{DN})^{2}+\mathrm{CF}
$$

where $\sigma^{\circ}$ is the backscattering intensity represented in decibel units (dB) and CF (equal to -83.4) is the calibration factor for the data obtained, depending on the observation period and polarization [22].

\subsection{Dielectric Constant Analysis}

The dielectric constant is the complex measurement form water, mineral soil, organic and salinity. The real and imaginary parts of the complex dielectric constant of different soil texture in different land cover with varied moisture content have been determined experimentally under laboratory conditions. Dielectric permittivity $\left(\varepsilon^{*}\right)$ is a complex function with real and imaginary components and is defined as:

$$
\varepsilon^{*}=\varepsilon^{\prime}-\mathrm{j} \varepsilon^{\prime \prime}
$$




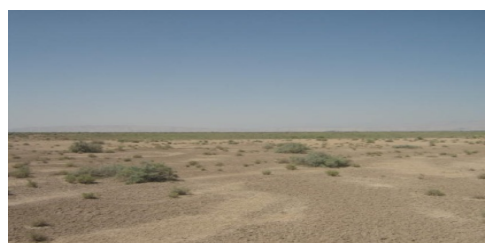

(a)

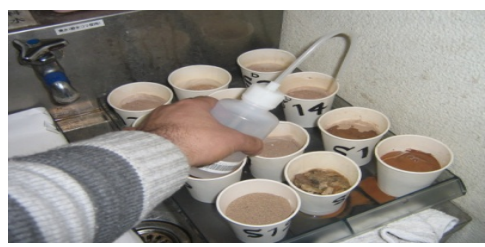

(c)

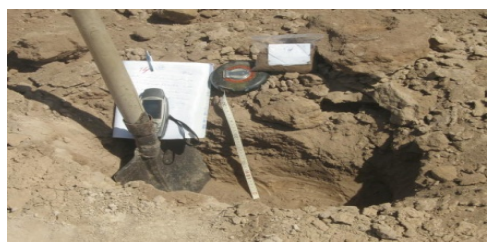

(b)

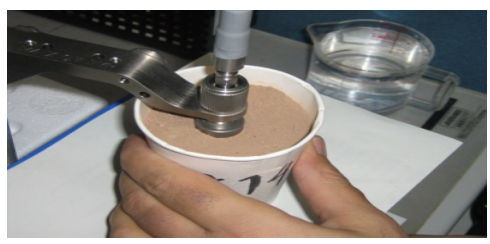

(d)

Figure 2. The land cover of sparse vegetation (a), field soil sampling (b), the soil moisture changing in laboratory (c) and the dielectric constant measurement at microwave remote sensing laboratory (d).

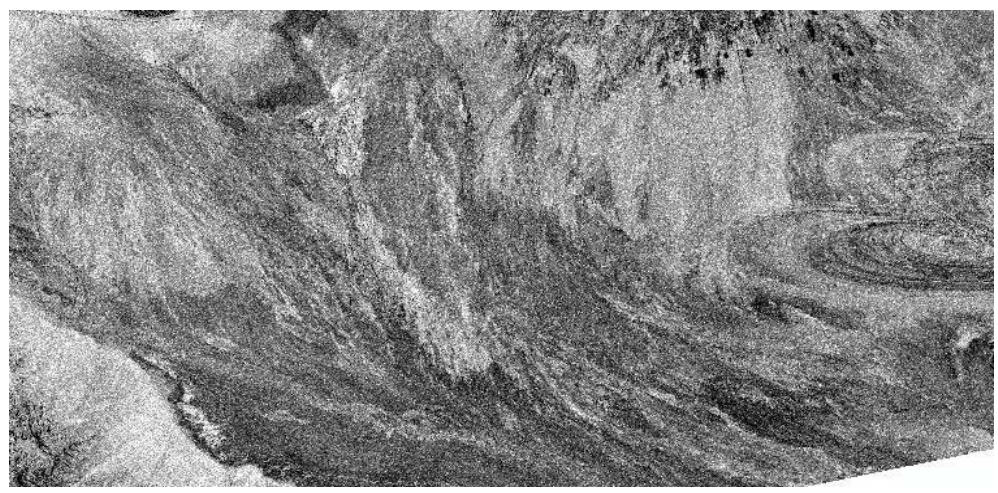

Figure 3. The ALOS PALSAR image (HH mode in $\mathrm{dB}$ ) of study area.

where $j$ is the square root of -1 . The real part $\left(\varepsilon^{\prime}\right)$ is often expressed as the relative permittivity $(\varepsilon r)$, which is the ratio of the electric-field storage capacity to that of free space [8] [11] [16]. The relative permittivity is a frequency dependent variable and decreases with increasing frequency [5]. The imaginary part $\left(\varepsilon^{\prime \prime}\right)$ of the dielectric permittivity is usually expressed in terms of dielectric losses, which include dispersive losses, as well as free-water relaxation and bound-water relaxation losses.

In this study, we have completed dielectric constant measurements for thirty five samples with different moisture contents (from dry soil to $40 \%$ moisture content in a seven steps). The dielectric constant of soil samples was measured in a microwave remote sensing laboratory using a network analyzer with an open air probe technique (Agilent 85070E dielectric tool kit) [23]. The measurement frequency was from 0.3 to $3 \mathrm{GHz}$ with 200 sampling points. We tried to this frequency range because we have supposed to cover the L-band $(1.27 \mathrm{GHz})$ same as ALOS PALSAR data.

\subsection{Statistical Analysis between Field Observation Data and Satellite Data}

Statistical model distinguished such a method to investigate the relationship between the remote sensing DN values with the geo-physical characteristics normally is based on the statistical relationship. We have carried out a statistical analysis for formulating relationships among the laboratory experiment and field observation data of the soil moisture content and the SAR data. The process will be taken by analyzing the relationships between SAR backscattering intensity $\left(\sigma^{\circ}\right)$ and the dielectric constant $\left(\varepsilon^{\prime}\right)$, soil moisture content in different soil type.

$10 \mathrm{~m}$ pixel spacing PALSAR image compare with varied soil moisture content in different soil type. The procedure for the relationship analysis was taken through multiple approaches: 
a) Each soil texture in different moisture content.

b) Specific soil texture in different level of moisture content (from $0 \%$ to $40 \%$ ).

c) Combine the all samples to gather in same soil moisture condition.

We tried to do the above approaches due to the SAR backscatter mechanisms complexity in the soil surface areas are. Typically, the backscattering of soil has relationship with soil moisture and trough the understanding the soil moisture necessity to find out the dielectric constant of soil in different level of moisture and soil texture as well. It is difficult to observe any trends when we come across making relationships with the backscattering and dielectric constant of different soil texture with varied soil moisture content. For the reason that, the backscattering even so affected by moisture content but, the surface roughness and vegetation water content and sensor characteristics like frequency and incident angle also affected to SAR backscattering. Then, we tried to break the whole samples to a smaller group and see how the backscattering will respond to those structures.

\section{Results and Discussion}

\subsection{Relationship Analysis among the Soil Moisture Dielectric Constant and Backscattering}

Overall, more than 520 measurements, for a total of 40 samples, of $\varepsilon^{\prime}$ and $\varepsilon^{\prime \prime}$ were performed, from 0.3 to 3 $\mathrm{GHz}$, on four different soil texture subjected to various moisture conditions. The first step in the analysis of the data was to compare the measured values with those calculated on the natural soil basis of the $\varepsilon^{\prime}$ and $\varepsilon^{\prime \prime}$ outlined in the dielectric constant tool kit (Figure 2 and Figure 3).

The volumetric water content range at laboratory was in $10 \%$ to $40 \%$. The graph trend shown that typically, the real part $\varepsilon^{\prime}$ slowly decreases with an rising of frequency, the imaginary part $\varepsilon^{\prime \prime}$ rapidly reducing with an increase of frequency, especially in the low frequency range, however we did not used the wide frequency range and it was tough to discriminate. Furthermore, the $\varepsilon^{\prime \prime}$ value is always bigger than the $\varepsilon^{\prime \prime}$ and it never gives the negative value. Other researchers have shown the dependence of $\varepsilon^{\prime}$ and $\varepsilon^{\prime \prime}$ on soil composition as well [2] [8] [10] [13]. According to interaction of soil texture, it seems the soil texture after the moisture content has the largest effect on the dielectric constant with assign the same frequency. Although, by this expression we are able to find the relationship with dielectric constant and backscattering that has linear relationship but the vegetation water content if the land cover is not bare area should be minded. Other items which have an important role in the soil surface roughness can influence backscattering coefficient [11] [12].

The backscatter always has linear correlation with dielectric constant since with increasing the dielectric constant the backscatter is increasing. The dielectric constant has linear correlation with soil moisture as well. We plot the dielectric constant against the backscattering intensity of two $\mathrm{HH}$ and $\mathrm{HV}$ polarization of study area in Figure 4. Figure 4 has shown that when the soil moisture increases the backscattering rises due to the dielectric constant. But, the relationship is polynomial since if the soil is very wet and/or muddy, the backscattering starts to decrease. The graph shows that the HV polarization mode is also more sensitive than HH mode to soil moisture and HV compared to HH mode which has higher backscattering. The dielectric constant plots out with va-

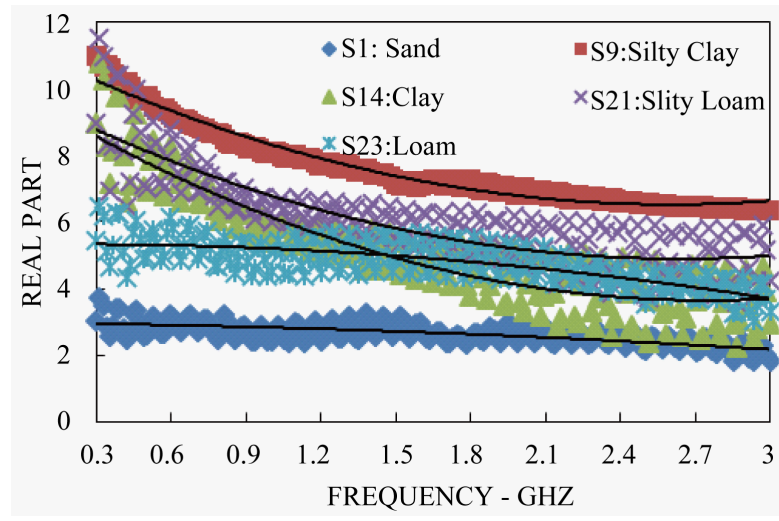

(a)

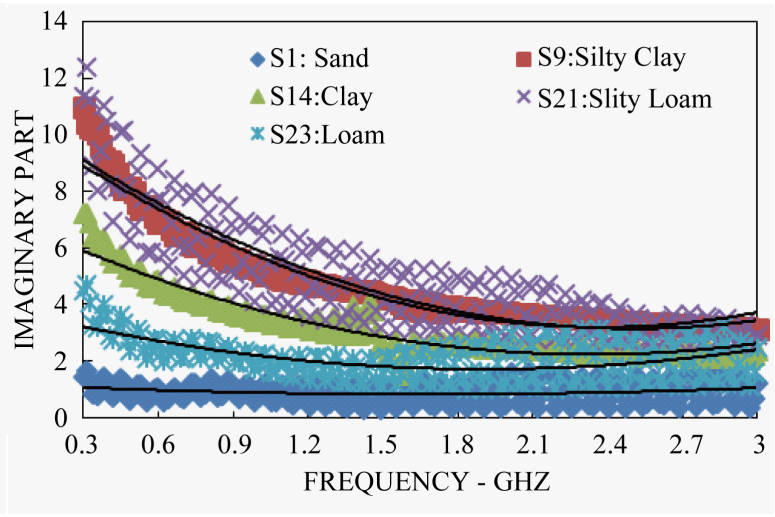

(b)

Figure 4. Frequency variations of the real (a) and imaginary (b) parts of the dielectric constant of the sample derived from laboratory measurements at $10 \%$ moisture content levels. 
ried soil moisture content of different soil texture in Figure 5. The result showing each specific soil has different trends which are based on that how much the soil can reserve or save the moisture content depend on the physical and chemical characteristics. For intense, the clay soil can keep the much amount of soil moisture than the sandy soil.

The particle size of different soil textures can affect the speed and height of water movement through capillary action in the soil. In general, the capillary water in loamy soil rises relatively quicker and to a greater height compared to clay and sandy soils. The four different soil textures are analyzed, and the representative texture types of this region are sandy and clay, silt and loam soils, which are thoroughly analyzed at L-band frequency (Figure 5 and Figure 6).

\subsection{Statistical Analysis of Backscattering vs. Soil Moisture}

Many approaches have been developed to retrieve soil moisture from microwave measurements, which can be grouped into two main categories: statistical techniques and forward model inversion [10]. Statistical approaches are generally based on the regression analysis between measured physical parameter, backscattering and surface soil moisture. For each group of satellite observations, regression relationships are established between measured parameter and backscattering. Statistical approaches are simple and efficient, which have demonstrated the capabilities of microwave remote sensing techniques for monitoring soil moisture.

Linear inversion is based on a simple least squares fitting of the desired parameter and model simulations of the backscattering coefficient, and is often applied at larger spatial scales [17] [19]. While the accepted relation-

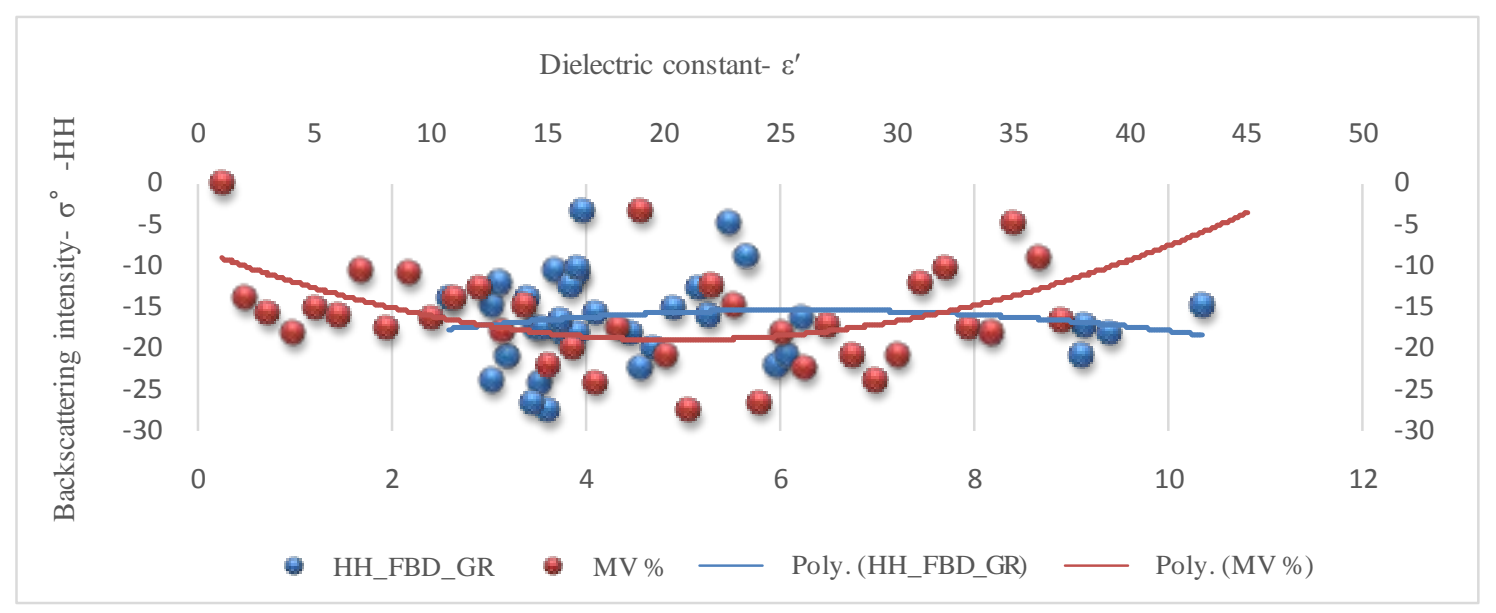

(a)

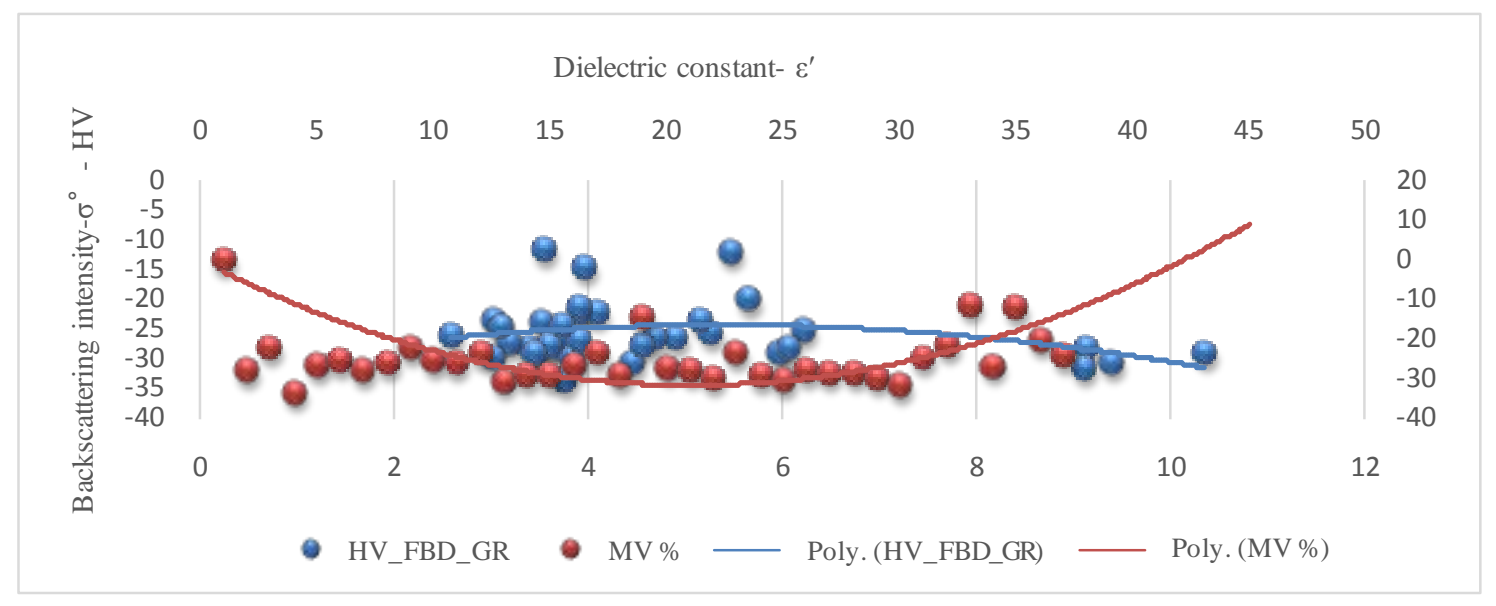

(b)

Figure 5. The comparison between the soil moisture and backscattering intensity in HH (a) and HV (b). 


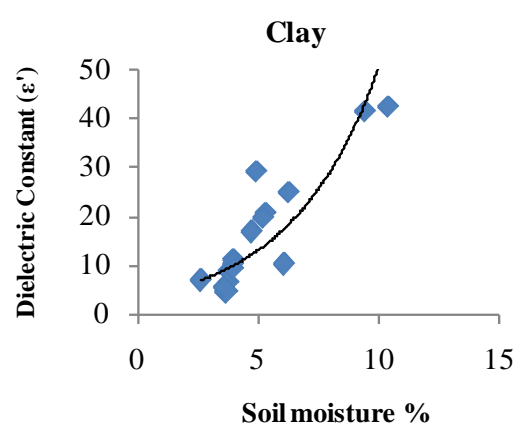

(a)

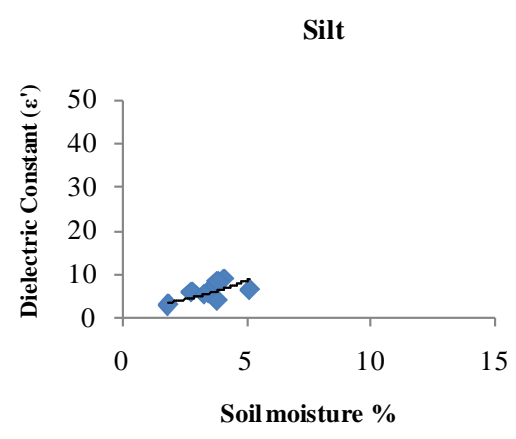

(b)

Figure 6. Dielectric constant behavior of clay (a) and silt soil texture (b) with varies moisture content.

ship between backscatter and soil moisture is non-linear, the relationship between radar backscattering signal and surface soil moisture could be approximated by a linear function. If the relationship is assumed non-linear, the form of the non-linear model used in inversion varies from exponential to polynomial [17].

In this research, we derived the land unit map and found the surface roughness average with field observation and made the polynomial regression in multi inversion for retrieving the soil moisture map. In order to retrieve the soil moisture, a regression model (Equation (3)) with dielectric constant data and backscattering was made and applied to PALSAR data in HH and HV polarization mode (Figure 7 and Figure 8).

The result of soil moisture map indication of the low moisture content is located in bare area and the higher are in lowland, herbaceous and crop residue since the vegetaion water content in the vegated cover areas achives the higher backscatter. It also depends on the surface roughness of the type of land cover.

$$
\begin{gathered}
\mathrm{Mv}^{2}=-0.2852 \sigma_{\mathrm{HV}}^{\circ}+3.0403 \sigma_{\mathrm{HV}}^{\circ}-32.518 \\
\mathrm{Mv}^{2}=0.0042 \sigma_{\mathrm{HH}}^{\circ}-0.1821 \sigma_{\mathrm{HH}}^{\circ}-15.324
\end{gathered}
$$

\section{Conclusion}

As expected, both real and imaginary parts of the dielectric constant increase with water content. The result of dielectric constant properties has shown therewas notconsiderably variation of the real and imaginary part of the dielectric constant with frequency of L-band $(1-2 \mathrm{GHz})$ also it was appreciated for any soil texture and moisture content. However, at frequencies above about 1 to $1.5 \mathrm{GHz}$ the $\varepsilon^{\prime \prime}$ rises with increasing water content. At frequencies below $1.5 \mathrm{GHz} \quad \varepsilon^{\prime}$ is only weakly frequency dependent and dielectric losses are generally low. The dielectric constant $\varepsilon^{\prime}$ is more sensitive than $\varepsilon^{\prime \prime}$ to soil moisture in low frequency but, for saline soil $\varepsilon^{\prime \prime}$ is more sensitive and is good for identifying the saline soil area. Soil moisture content has the biggest effect on the dielectric constant. Soil texture was the second biggest impact on the value of the dielectric constant, followed by soil salinity. However, the moisture content also depends on soil texture and soil type. The clay soil has demonstrated the highest emissivity values, followed by loam, silt and sandy soils types, in that order. The land cover also has good agreement by dielectric constant in each level of soil moisture content even in same soil types led to affect the vegetation water content on the soil and also effect on the backscatter because of the roughness. For instance in vegetated cover soil even the vegetation suction the water from soil but still the dielectric constant was higher than the bare soil, it might be cause of the soil in more developed and evaporation from the soil surface is less than the bare soil. The image classification need to improve the regression model and increase the correlation, addition in relief area observed the some noise which because of roughness and geometric characteristics. The soil moisture result of SAR Image compression shown the HV mode has overestimated soil moisture particular in sparse vegetation land cover and sandy soil with light roughness. Trying to soil moisture deriving by inversion, empirical and semi-empirical model would be helpful for finding the best model in the study area with better accuracy. We validated the soil moisture map using ground truth soil moisture and then we observed the $4.2 \mathrm{Vol}$-\%RMSE in soil moisture accuracy for the soil moisture map. Although, the accuracy is not high, it is acceptable. Since the statistical method is similar to the forward model, therefore it 


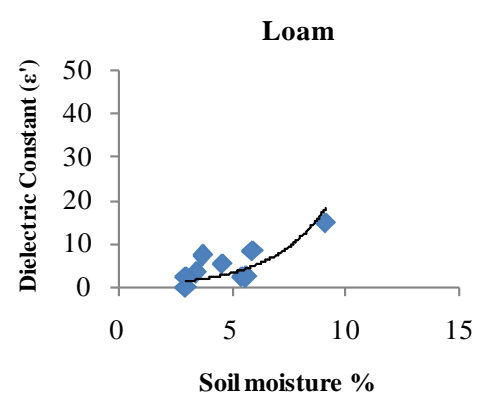

(a)

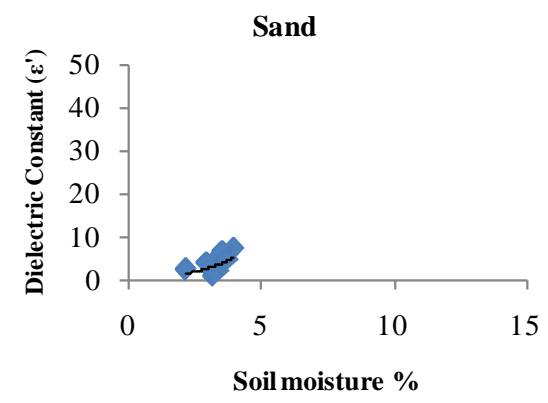

(b)

Figure 7. Dielectric constant behavior of loam (a) and sand soil types (b) with varies moisture content.
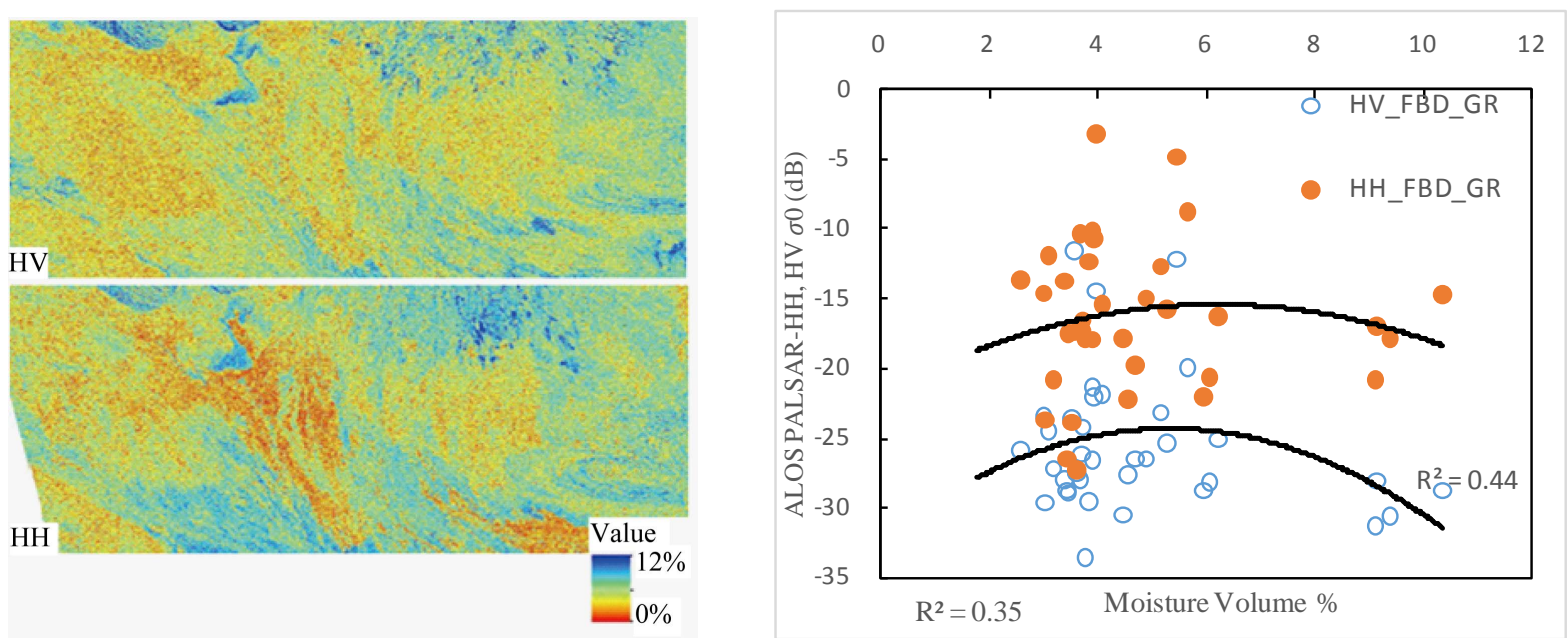

Figure 8. The relationship between backscattering intensity PALSAR data and dielectric constant measurement. Retrieving the soil moisture map using ALOS PALSAR dual mode.

might be the other item such as roughness that is not considerable and the one lacking of potentiality of this method. This technique is proposed by researchers when we have no other data for mapping and also at first timewhen this method is possible to get overview of the study area. The correlation between the variable seems low even the other researchers also were not be able to provide more higher than it. It is because of the backscattering complexity and the reasons which are mentioned above and particularly mixed pixel of vegetation and its attention and water content. Recently, by the new SAR sensor such as ALOS-2 and better revisit time it might be able to improve the difficulties.

\section{References}

[1] Ghosh, A., Bihari, J. and Pyne, S. (1998) Dielectric Parameters of Dry and Wet Soils at 14.89 GHz. Indian Journal of Radio \& Space Physics, 27, 130-134.

[2] Usowicz, B., Marczewski, W., Usowicz, J.B. and Lipiec, J. (2010) Statistical Modelling of the Soil Dielectric Constant. Geophysical Research Abstracts, 12, EGU2010-6749.

[3] Lee, E., Chase, T.N., Rajagopalan, B., Barry, R.G., Biggs, T.W. and Lawrence, P.J. (2009) Effects of Irrigation and Vegetation Activity on Early Indian Summer Monsoon Variability. International Journal of Climatology, 573-558. http://dx.doi.org/10.1002/joc.1721

[4] Curtis, J.O. (2001) Moisture Effects on the Dielectric Properties of Soils. IEEE Transaction on Geoscience and Remote Sensing, 39, 125-128.

[5] Calla, O.P.N. and Singh, R.K. (2002) Emission Characteristics of Dry and Wet Loamy Sand Soil Layered Packed at Microwave Frequency. Indian Journal of Radio \& Space Physics, 31, 285-292.

[6] Hallikainen, M.T., Ulaby, F.T., Dobson, M.C., El-Rayes, M.A. and Wu, L.-K. (1985) Microwave Dielectric Behavior 
of Wet Soil-Part I: Empirical Models and Experimental Observations. IEEE Transactions on Geoscience and Remote Sensing, GE-23, 25-34. http://dx.doi.org/10.1109/TGRS.1985.289497

[7] Wang, L. and QU, J.J. (2009) Satellite Remote Sensing Applications for Surface Soil Moisture Monitoring: A Review. Frontiers of Earth Science in China, 3, 237-247. http://dx.doi.org/10.1109/TGRS.1980.350304

[8] Campbell, J.E. (1990) Dielectric Properties and Influence of Conductivity in Soils at One to Fifty Megahertz. Soil Science Society of America Journal, 54, 332-341. http://dx.doi.org/10.2136/sssaj1990.03615995005400020006x

[9] Arya, L.M. and Paris, J.F. (1981) A Physicoempirical Model to Predict the Soil Moisture Characteristic from Particle-Size Distribution and Bulk Density Data. Soil Science Society of America Journal, 45, 1023-1030. http://dx.doi.org/10.2136/sssaj1981.03615995004500060004x

[10] Wang, J.R. and Schmugge, T.J. (1980) An Empirical Model for the Complex Dielectric Permittivity of Soils as a Function of Water Content. IEEE Transactions on Geoscience and Remote Sensing, 18, 288-295. http://dx.doi.org/10.1007/s11707-009-0023-7

[11] Haillikainen, M., Ulaby, F.T., Dobson, M.C., El-Rayes, M.A. and Wu, L.K. (1985) Microwave Dielectric Behavior of Wet Soil-Part 1: Empirical Models and Experimental Observations. IEEE Transactions on Geoscience and Remote Sensing, GE-23, 25-34.

[12] Dobson, M.C., Ulaby, F.T., Hallikainen, M.T. and El-Rayes, M.A. (1985) Microwave Dielectric Behavior of Wet SoilPart II: Dielectric Mixing Models. IEEE Transactions on Geoscience and Remote Sensing, GE-23, 35-46. http://dx.doi.org/10.1109/TGRS.1985.289498

[13] Chaudhari, H.C. and Shinde, V.J. (2012) Dielectric Properties of Soil at X-Band Microwave Frequency. Indian Journal of Pure and Applied Physics, 50, 64-66.

[14] Peplinski, N.R., Ulaby, F.T. and Dobson, M.C. (1995) Dielectric Properties of Soils in the 0.3-1.3-GHz Range. IEEE Transactions on Geoscience and Remote Sensing, 33, 803-807.

[15] http://www.nrcs.usda.gov

[16] Gadani, D.H. and Vyas, A.D. (2008) Measurement of Complex Dielectric Constant of Soils of Gujarat at X- and C-Band Microwave Frequencies. Indian Journal of Radio \& Space Physics, 37, 221-229.

[17] Baghdadi, N., Aubert, M., Cerdan, O., Franchisteguy, L., Viel, C., Eric, M., Zribi, M. and Desprats, J.F. (2007) Operational Mapping of Soil Moisture Using Synthetic Aperture Radar Data: Application to the Touch Basin (France). Sensors, 7, 2458-2483. http://dx.doi.org/10.3390/s7102458

[18] Li, Y.Y., Zhao, K., Ren, J.H., Ding, Y.L. and Wu, L.L. (2014) Analysis of the Dielectric Constant of Saline-Alkali Soils and the Effect on Radar Backscattering Coefficient: A Case Study of Soda Alkaline Saline Soils in Western Jilin Province Using RADARSAT-2 Data. The Scientific World Journal, 2014, 1-14. http://dx.doi.org/10.1155/2014/56301

[19] Anguela, T.P., Zribi, M., Baghdadi, N. and Loumagne, C. (2010) Analysis of Local Variation of Soil Surface Parameters with TerraSAR-X Radar Data over Bare Agriculture Fields. IEEE Transactions on Geoscience and Remote Sensing, 48, 874-881. http://dx.doi.org/10.1109/TGRS.2009.2028019

[20] Wignerona, J.P., Calvetb, J.C., Pellarinb, T., Van de Griendc, A.A., Bergerd, M. and Ferrazzolie, P. (2003) Retrieving Near-Surface Soil Moisture from Microwave Radiometric Observations: Current Status and Future Plans. Remote Sensing of Environment, 85, 489-506. http://dx.doi.org/10.1016/S0034-4257(03)00051-8

[21] Bolten, J.D., Lakshmi, V. and Njoku, E.G. (2003) Soil Moisture Retrieval Using the Passive/Active L- and S-Band Radar/Radiometer. IEEE Transactions on Geoscience and Remote Sensing, 41, 2792-2801. http://dx.doi.org/10.1109/TGRS.2003.815401

[22] Japan Aerospace Exploration Agency (2009) PALSAR Calibration Factor Updated. http://www.eorc.jaxa.jp/en/about/distribution/info/alos/20090109en_3.html

[23] Agilent. http://www.keysight.com 